\title{
Photocatalytic Decomposition of Phenol by Nanocomposite of ZnS Nanoparticles and Montmorillonite
}

\author{
Petr Praus, * Jakub Matys and Ondřej Kozák \\ Department of Analytical Chemistry and Material Testing, V̌̌B-Technical University of Ostrava, \\ 17, Listopadu 15, 70833 Ostrava-Poruba, Czech Republic
}

\begin{abstract}
O nanocompósito de partículas de $\mathrm{ZnS}$ estabilizadas por íons cetiltrimetilamônio (ZnS-CTA) e montmorilonita (ZnS-CTA-MMT) foi preparado e usado como catalisador na fotodecomposição de fenol sob radiação UV de uma lâmpada de $\mathrm{Hg}$ de pressão média. A quantidade de $\mathrm{ZnS}$ em ZnS-CTA-MMT foi aproximadamente $6 \mathrm{wt}$ \%. Para comparação, a fotodecomposição foi também realizada com $\mathrm{ZnS}-\mathrm{CTA}$, montmorilonita e sem catalisador, isto é, usando apenas irradiação UV. A eficiência da fotodecomposição decresceu na ordem: UV + ZnS-CTA-MMT ca. UV + ZnS-CTA > UV > UV + MMT. A fotodecomposição na presença de ZnS-CTA-MMT e $\mathrm{ZnS}-\mathrm{CTA}$ ocorreu de acordo com a cinética de pseudo-primeira ordem. Em outros casos, a fotodecomposição correspondeu à cinética de pseudo-segunda ordem de fenol e radicais hidroxila. Radicais hidroxila foram produzidos pelas reações de oxigênio dissolvido e elétrons liberados a partir das nanopartículas $\mathrm{ZnS}$ e moléculas de fenol excitadas. MMT reduziu a velocidade da reação de fotodecomposição e não foi observada a atividade catalítica de MMT.
\end{abstract}

The nanocomposite of $\mathrm{ZnS}$ nanoparticles stabilized by cetyltrimethylammonium ions (ZnS-CTA) and montmorillonite (ZnS-CTA-MMT) was prepared and used as a catalyst for the photodecomposition of phenol under UV irradiation of a medium pressure Hg lamp. The content of $\mathrm{ZnS}$ in $\mathrm{ZnS}-\mathrm{CTA}-\mathrm{MMT}$ was about $7 \mathrm{wt}$.\%. For comparison, the photodecomposition was also performed with $\mathrm{ZnS}-\mathrm{CTA}$, montmorillonite and with no catalyst, i.e., using only UV irradiation. The photodecomposition efficiency decreased in the order: UV + ZnS-CTA-MMT $\approx \mathrm{UV}+$ $\mathrm{ZnS}-\mathrm{CTA}>\mathrm{UV}>\mathrm{UV}+\mathrm{MMT}$. The photodecomposition in the presence of ZnS-CTA-MMT and $\mathrm{ZnS}-\mathrm{CTA}$ proceeded according to the pseudo-first order reaction kinetics. In other cases, the photodecomposition corresponded to the pseudo-second order reaction of phenol and hydroxyl radicals. Hydroxyl radicals were produced by reactions of dissolved oxygen and electrons released from the $\mathrm{ZnS}$ nanoparticles and excited phenol molecules. MMT decreased the photodecomposition reaction rate and no MMT catalytic activity was observed.

Keywords: ZnS nanoparticles, montmorillonite, nanocomposite, photocatalysis, phenol

\section{Introduction}

Typical properties of nanoparticles are high specific surface area and high reactivity that makes them suitable for adsorption of various compounds and for photocatalysis. In addition, in case of semiconductor nanopaticles, decrease of their size leads to increase of their band-gap energy known as the quantum size effect or quantum confinement. Oxidation and/or reduction reactions on semiconductor nanoparticles begin with excitation of electrons from the valence band to conduction band. This may occur

*e-mail: petr.praus@vsb.cz when electrons in the valence band absorb photons with energy equals to or higher than band-gap energy of the nanoparticle. At the same time holes in the valence band are generated. Both electrons and holes can recombine forming heat or luminescence irradiation or can take part in reduction or oxidation reactions with electron acceptors or donors adsorbed on the nanoparticle surface. ${ }^{1,2}$

Electrons are caught by dissolved oxygen molecules forming superoxide ion-radicals $\mathrm{O}_{2}{ }^{--}$that are in equilibrium with their conjugate acids, hydroperoxyls $\mathrm{HO}_{2}{ }^{\circ}\left(\mathrm{pK}_{\mathrm{a}}=4.8\right){ }^{3}$ Two $\mathrm{HO}_{2} \cdot$ radicals form hydrogen peroxide and oxygen. In the following step hydrogen peroxide decomposes into hydroxyl radical and hydroxide anion. These reactions can be described by the following scheme: 
$\mathrm{e}^{-}+\mathrm{O}_{2} \rightarrow \mathrm{O}_{2}^{\cdot-}$

$\mathrm{O}_{2}{ }^{--}+\mathrm{H}^{+} \rightleftharpoons \mathrm{HO}_{2} \cdot$

$2 \mathrm{HO}_{2} \cdot \rightarrow \mathrm{H}_{2} \mathrm{O}_{2}+\mathrm{O}_{2}$

$\mathrm{H}_{2} \mathrm{O}_{2}+\mathrm{e}^{-} \rightarrow \mathrm{OH}^{\bullet}+\mathrm{OH}^{-}$

The holes react with water forming hydroxyl radicals as follows:

$\mathrm{h}^{+}+\mathrm{H}_{2} \mathrm{O} \rightarrow \mathrm{OH}^{\bullet}+\mathrm{H}^{+}$

Many papers were dedicated to using clay minerals as photocatalysts. ${ }^{4-10}$ Their catalytic activity was ascribed to the photo-Fenton reaction of ferric ions located in their structures ${ }^{4-6}$ or leached to the aqueous phase. Hydrated $\mathrm{Fe}^{3+}$ ions absorb photons forming hydroxyl radicals as

$\mathrm{Fe}^{3+}+\mathrm{H}_{2} \mathrm{O} \rightarrow \mathrm{Fe}(\mathrm{OH})^{2+}+\mathrm{H}^{+}$

$\mathrm{Fe}(\mathrm{OH})^{2+}+\mathrm{h} v \rightarrow \mathrm{Fe}^{2+}+\mathrm{OH}^{\bullet}$

Ferrous ions are then back oxidized to ferric ones by oxidants such as dissolved oxygen and hydrogen peroxide. The reaction of $\mathrm{Fe}(\mathrm{OH})^{2+}$ (equation 7) is based on absorption of UV irradiation that can be often decreased by the presence of other absorbing compounds. This condition is very limiting for the decomposition of organic compounds especially in real systems containing also solid particles. Some comprehensive reviews on application of clays for the Fenton ${ }^{11}$ and photo-Fenton ${ }^{12}$ reactions were published in the literature as well.

Hydroxyl radicals are often used for the decomposition of organic compounds at e.g. wastewater treatment processes. ${ }^{13-15}$ They behave as electrophiles attacking aromatic $\pi$ electrons. Hydroxyl radicals are very strong oxidation agents with the high standard electrochemical potential of $\mathrm{E}^{\circ}=2.6 \mathrm{~V}$ to $2.8 \mathrm{~V}^{3,16}$

The aim of this paper was to prepare the nanocomposite of $\mathrm{ZnS}$ nanoparticles and phyllosilicates and use it for the UV decomposition of phenol. The $\mathrm{ZnS}$ nanoparticles were precipitated in the presence of stabilizing cetyltrimethylammonium bromide (CTAB). ${ }^{17,18}$ Advantages of the nanocomposite is the long-term stability of $\mathrm{ZnS}$ nanoparticles and easy handling with powder samples. Recently such nanocomposite was tested for the reduction of carbon dioxide. ${ }^{17}$

Phenol was chosen for these experiments because $(i)$ its photodecomposition mechanisms are well documented in the literature, $(i i)$ there are reliable analytical methods for its determination and (iii) phenol is a widely spread organic pollutant and new findings can help to understand its behaviour in the environment.

Under UV irradiation, the phenol decomposition in neutral and acidic solutions is presumed to be a two-step (biphotonic) process. ${ }^{19,20}$ The first photon is absorbed to form exited phenol (ArOH) in a single state and, consequently, the second photon is absorbed by phenol in its triple state producing electron and phenoxyl radical cation $\left(\mathrm{ArOH}^{++}\right)$as follows

$\mathrm{ArOH}+\mathrm{h} v \rightarrow \mathrm{ArOH}^{\bullet+}+\mathrm{e}^{-} \rightarrow \mathrm{ArO}^{\bullet}+\mathrm{e}^{-}+\mathrm{H}^{+}$

The radical cation is rapidly deprotonated yielding phenoxyl radical. The electron can be trapped by dissolved oxygen forming hydroxyl radicals according to the reactions 1-4. Reactions of hydroxyl radicals and phenol or phenoxyl radical can form many intermediates, such as 1,2- and 1,4-dihydroxybenzenes and consequently $o$ and $p$-benzoquinones. Benzoquinones can be gradually oxidized by hydroxyl radicals to carboxylic acids, such as oxalic, formic, ${ }^{14}$ acetic, ${ }^{21}$ maleic, malonic, mucotic, fumaric $\operatorname{acid}^{22,23}$ that are finally oxidized to carbon dioxide. Other reactions of phenoxyl radicals can lead to the dimerization of phenol forming diphenylethers and biphenols. ${ }^{21}$

\section{Experimental}

\section{Materials}

All chemicals were of analytical reagent grade: phenol, $p$-nitroaniline, sodium nitrite, sodium hydrogencarbonate, zinc acetate, sodium sulphide (all from Lachema, Czech Republic), cetyltrimethylammonium bromide (Merck, Germany). Water deionised by reverse osmosis (Aqua Osmotic, Czech Republic) was used for the preparation of all solutions. Kaolinite KGa-1b (Clay Minerals Society, USA), vermiculite (Grena, Czech Republic) and montmorillonite Swy 2 (Wyoming, USA) were used for the deposition of $\mathrm{ZnS}$ nanoparticles.

\section{Preparation of $\mathrm{ZnS}$ and phyllosilicate nanocomposite}

$50 \mathrm{~mL}$ of the aqueous solution of $\mathrm{Na}_{2} \mathrm{~S}\left(15 \mathrm{mmol} \mathrm{L}^{-1}\right)$ and CTAB was added drop-wise to $250 \mathrm{~mL}$ of the aqueous solution of zinc acetate $\left(2 \mathrm{mmol} \mathrm{L}^{-1}\right)$ under vigorous stirring. The concentration of CTAB was $4 \mathrm{mmol} \mathrm{L}^{-1}$. An amount of $300 \mathrm{~mL}$ of freshly prepared dispersions was shaken with $0.5 \mathrm{~g}$ of phyllosilicates for $24 \mathrm{~h}$. Then, the dispersions were filtered and dried at $105^{\circ} \mathrm{C}$. 


\section{Phenol photodecomposition procedure}

Phenol photodecomposition was performed in a stirred batch reactor opened to the air. The medium pressure $\mathrm{Hg}$ lamp was used for all experiments. The light flux was measured by a radiometer (UVP, USA) in the distance, where the reaction took place: $83 \mathrm{~mW} \mathrm{~cm}^{-2}$ for $254 \mathrm{~nm}$ and $30 \mathrm{~mW} \mathrm{~cm} \mathrm{~cm}^{-2}$ for $365 \mathrm{~nm}$. The nanocomposite was mixed with $70 \mathrm{~mL}$ of the aqueous solution of phenol $\left(0.55 \mathrm{mmol} \mathrm{L}^{-1}\right)$. The mixture was stirred for $10 \mathrm{~min}$ before the UV lamp was switch on to provide good homogenization of the dispersions. The temperature in the reactor was kept at $27^{\circ} \mathrm{C}$.

\section{Analytical methods}

The phenol decomposition products were analysed by a gas chromatograph Varian CO 3800 (Varian Inc., Australia) equipped with a mass detector Varian Saturn 2000 (EI, $70 \mathrm{eV}$ ). The $60 \mathrm{~m}$ long DB5 column with an inner diameter of $0.25 \mu \mathrm{m}$ and helium as a carrier gas were used. The reaction dispersions were centrifuged and extracted by dichloromethane, which was evaporated at a water bath. The evaporated products were dissolved in a hexane-toluene mixture (80:20) and derivatized by acetic anhydride. The extracts were injected by means of a splitless injector at $280{ }^{\circ} \mathrm{C}$. The temperature during the $\mathrm{GC}$ separation was elevated from $70^{\circ} \mathrm{C}$ to $300{ }^{\circ} \mathrm{C}$.

The total concentrations of iron were determined by an atomic absorption spectrometer AA280FS (Varian Inc., Australia) with the acetylene-air atomization. Phenol was determined by the reaction with diazonium salt of $p$-nitroaniline. Absorbances of the resulting azo dye were measured at the wavelength of $470 \mathrm{~nm}$. All UV-Vis spectrophotometric measurements were performed by a spectrometer Lambda 35 (Perkin Elmer, USA). Dissolved oxygen was determined by the Winkler's volumetric method. Total organic carbon (TOC) was determined by a Shimadzu analyzer TOC 5000A.

Specific surface area (SSA) of the nanocomposites was measured with an instrument Sorptomatic 1990 (Thermo Electron Corporation, USA) using nitrogen as an adsorbing gas and calculated by the Advance Data Processing software according to the BET isotherm at the temperature of $77.3 \mathrm{~K}$ and at a ratio $\mathrm{p} / \mathrm{p}^{0}$ up to 0.3 , i.e., up to the beginning of capillary condensation.

The X-ray powder diffraction (XRD) study was performed by a powder diffractometer (Bruker D8 Advance, Germany) equipped with a scintillation and position-sensitive detector (Vantec, Germany) and a source of CoK $\alpha$ radiation. The diffraction patterns were recorded in an ambient atmosphere under constant conditions $(50 \mathrm{kV}, 60 \mathrm{~mA})$.

\section{Results and Discussion}

\section{Preparation and characterization of $\mathrm{ZnS}$ nanocomposite}

The $\mathrm{ZnS}$ nanoparticles were precipitated in the presence of CTAB in the concentration of $3 \mathrm{mmol} \mathrm{L}^{-1}$, i.e., above its critical micelar concentration (about $1 \mathrm{mmol} \mathrm{L}^{-1}$ ). Under these conditions CTAB molecules exist as free monomers and micelles. CTA ions can adsorb on the surface of $\mathrm{ZnS}$ nanoparticles forming positively charged ZnS-CTA micelles. ${ }^{18}$ The micelles were stabilized by their deposition on various phyllosilicates, such as kaolinite, vermiculite and montmorillonite. The dispersions of $\mathrm{ZnS}-\mathrm{CTA}$ and the phyllosilicates were shaken for $24 \mathrm{~h}$, filtered and the UV-Vis absorption spectra of the filtrates were recorded as demonstrated in Figure 1. The absorption spectrum of $\mathrm{ZnS}-\mathrm{CTA}$ was added in the Figure for comparison.

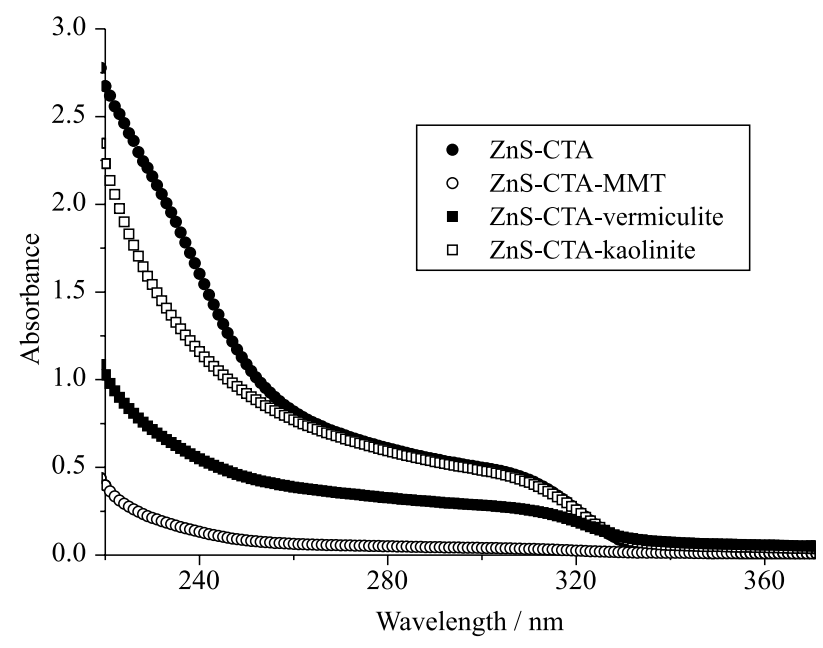

Figure 1. UV-Vis absorption spectra of filtrates of $\mathrm{ZnS}$ nanoparticles and phyllosilicates.

As shown, the lowest absorbances were measured in the filtrates of the montmorillonite dispersion because the ZnS-CTA micelles were deposited on MMT in higher amounts than on kaolinite and vermiculite. The deposition was enhanced by the negative charge of the MMT surface that attracted the positively charged micelles. ${ }^{18}$ Therefore, the $\mathrm{ZnS}-\mathrm{CTA}-\mathrm{MMT}$ nanocomposite was used for further experiments. The structural MMT formula of $\mathrm{Na}_{0.38} \mathrm{~K}_{0.04}\left(\mathrm{Ca}_{0.12} \mathrm{Mg}_{0.50} \mathrm{Fe}^{3+}{ }_{0.41} \mathrm{Al}_{2.90} \mathrm{Ti}_{0.01} \mathrm{Mn}_{0.01}\right)\left(\mathrm{Si}_{8}\right) \mathrm{O}_{20}(\mathrm{OH})_{4}$ was calculated from the results of $\mathrm{X}$-ray fluorescence and spectrophotometric analysis also to determine the content of $\mathrm{Fe}^{3+}$ that is necessary for the photo-Fenton reaction.

The stability of $\mathrm{ZnS}-\mathrm{CTA}-\mathrm{MMT}$ was verified by its shaking in water for $24 \mathrm{~h}$. These dispersions were filtered and the UV-Vis absorption spectra of the filtrates were recorded. They did not show the typical absorption edge of 
$\mathrm{ZnS}$ nanoparticles at about $320 \mathrm{~nm}$ (Figure 1), which means the $\mathrm{ZnS}$ nanoparticles were firmly attached to MMT likely located in its pores. ${ }^{24}$ To verify this, ZnS-CTA-MMT was dried at $105^{\circ} \mathrm{C}$ and $-24^{\circ} \mathrm{C}$ and its specific surface area was measured. Total SSA of the micro- and mesopores of the heated and frozen nanocomposite was 5.2 and $18.4 \mathrm{~m}^{2} \mathrm{~g}^{-1}$, respectively. It indicates that some pores containing the $\mathrm{ZnS}$ nanoparticles were closed by heating at $105^{\circ} \mathrm{C}$.

In our earlier study ${ }^{17}$ it was found that the nanocomposite consisted of about $7 \mathrm{wt} . \%$ of $\mathrm{ZnS}, 30 \mathrm{wt} . \%$ of CTA and $63 \mathrm{wt} . \%$ of MMT. The ZnS nanoparticles with the mean size of $4 \mathrm{~nm}$ and wurtzite structure were observed by transmission electron microscopy. It was also found by XRD that CTA was intercalated into the MMT interlayer.

\section{Photodecomposition of phenol}

The aqueous dispersions of MMT, ZnS-CTA-MMT and $\mathrm{ZnS}-\mathrm{CTA}$ were applied for the photodecomposition of phenol by UV irradiation in the batch reactor. MMT was applied in two concentrations: (i) $1.3 \mathrm{~g} \mathrm{~L}^{-1}$ corresponding to the MMT content in the ZnS-CTA-MMT nanocomposite and (ii) at the concentration of $7.1 \mathrm{~g} \mathrm{~L}^{-1}$ marked as MMT(1). The content of ZnS in the ZnS-CTA-MMT and ZnS-CTA dispersions was similar.

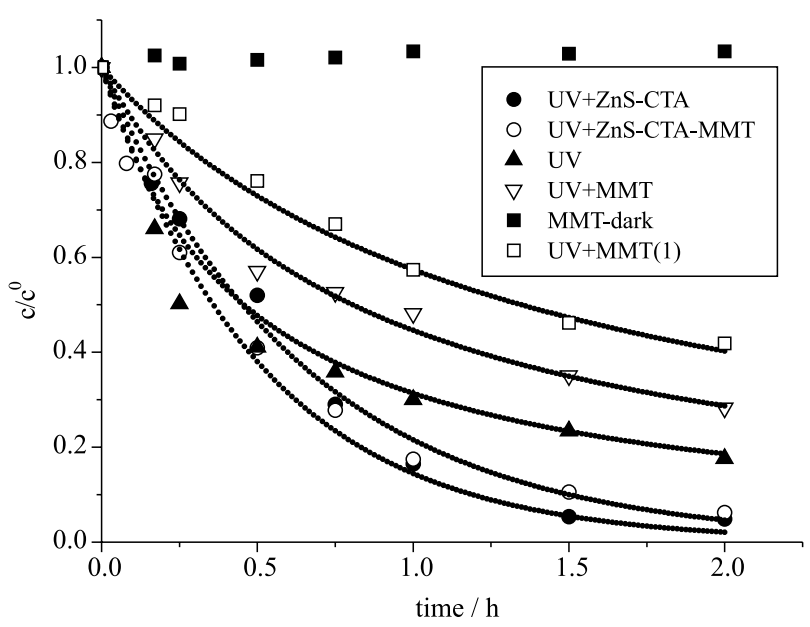

Figure 2. Reaction kinetics of phenol decomposition under various conditions.

During $2 \mathrm{~h}$ the concentrations of phenol gradually decreased as shown in Figure 2. If no UV irradiation was applied (in dark) in the presence of MMT the phenol concentrations were nearly constant. It indicates that phenol was not adsorbed by MMT and the reactor walls. The photodecomposition efficiency decreased in the order: UV + ZnS-CTA-MMT $\approx$ UV+ ZnS-CTA $>$ UV $>$ $\mathrm{UV}+\mathrm{MMT}$. In comparison with the application of only UV irradiation, ZnS-CTA-MMT as well as ZnS-CTA enhanced and, on the other hand, MMT deteriorated the phenol photodecomposition. The explanation of these phenomena is in the different concentrations of hydroxyl radicals produced under the various conditions.

Using the medium pressure $\mathrm{Hg}$ lamp hydroxyl radicals cannot be produced by the dissociation of water molecules ${ }^{19}$ but they can be generated by the reactions of dissolved oxygen in water with electrons released from the $\mathrm{ZnS}$ nanoparticles and excited phenol molecules in accordance with equations 1-4.

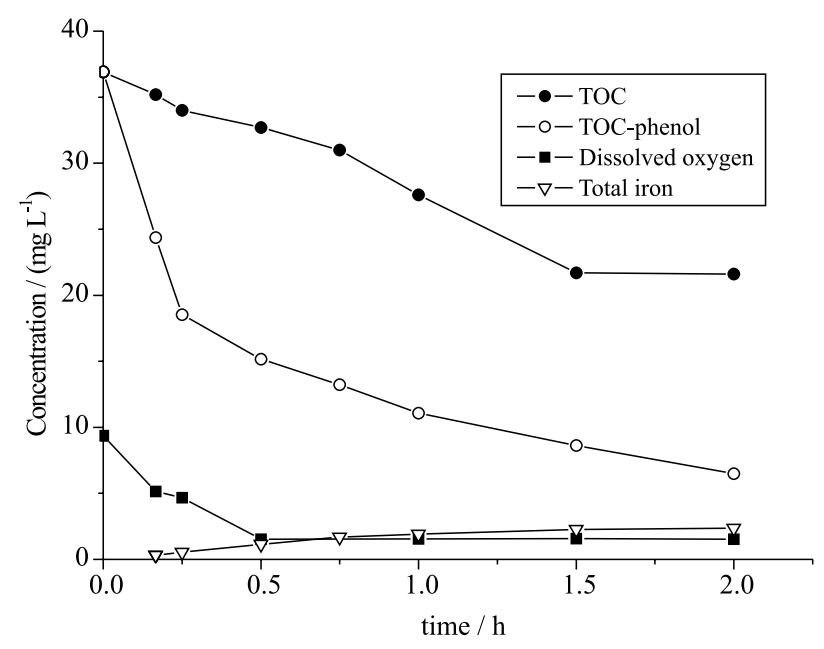

Figure 3. Concentrations of dissolved oxygen and TOC without MMT and total iron concentrations with MMT $\left(7.1 \mathrm{~g} \mathrm{~L}^{-1}\right)$ during the phenol photodecomposition.

The concentration of dissolved oxygen was measured during the UV photodecomposition without the catalysts. It steeply decreased within the first $30 \mathrm{~min}$ down to the concentration of $1.5 \mathrm{mg} \mathrm{L}^{-1}$ and then became constant (Figure 3). The determination limit of the used volumetric method was about $0.5 \mathrm{mg} \mathrm{L}^{-1}$ therefore we can deduce that a steady state between the consumption of oxygen for the formation of hydroxyl radicals and its transport from the air was reached.

\section{Analysis of kinetic data}

In general, the reactions of phenol and hydroxyl radicals on the surface of solid catalysts can be described by the Langmuir-Hinshelwood model ${ }^{25}$

$\mathrm{r}=-\frac{\mathrm{dc}_{\mathrm{P}}}{\mathrm{dt}}=\mathrm{k}_{\mathrm{h}} \frac{\mathrm{K}_{\mathrm{P}} \mathrm{c}_{\mathrm{P}}}{1+\mathrm{K}_{\mathrm{P}} \mathrm{c}_{\mathrm{P}}+\sum \mathrm{K}_{\mathrm{i}} \mathrm{c}_{\mathrm{i}}} \frac{\mathrm{K}_{\mathrm{OH}} \mathrm{c}_{\mathrm{OH}}}{1+\mathrm{K}_{\mathrm{OH}} \mathrm{c}_{\mathrm{OH}}}$

where $\mathrm{k}_{\mathrm{h}}$ is the kinetic parameter; $\mathrm{K}_{\mathrm{p}}, \mathrm{K}_{\mathrm{OH}}, \mathrm{K}_{\mathrm{i}}$ and $\mathrm{c}_{\mathrm{P}}, \mathrm{c}_{\mathrm{OH}}, \mathrm{c}_{\mathrm{i}}$ are the adsorption constants and concentrations of remaining phenol, hydroxyl radicals and intermediates, respectively. 
In case of the catalytic activity of ZnS-CTA-MMT and $\mathrm{ZnS}-\mathrm{CTA}$ the production of high concentrations of hydroxyl radicals can be expected. If $\mathrm{c}_{\mathrm{OH}}>>\mathrm{c}_{\mathrm{p}}$ and $\Sigma \mathrm{K}_{\mathrm{i}} \mathrm{c}_{\mathrm{i}}$ is neglected ${ }^{25}$ then equation 9 can be simplified to its mostly used form

$\mathrm{r}=\mathrm{k}_{\mathrm{app}} \frac{\mathrm{K}_{\mathrm{P}} \mathrm{c}_{\mathrm{p}}}{1+\mathrm{K}_{\mathrm{P}} \mathrm{c}_{\mathrm{P}}}$

where $\mathrm{k}_{\text {app }}$ is the apparent kinetic parameter depending on irradiation intensity, mass and nature of the solid phase (catalyst) and the concentration of hydroxyl radicals. It was theoretically approved this model is appropriate for the first order kinetics. ${ }^{26}$ Adsorption of phenol on natural MMT and MMT modified with CTA is 1 low ${ }^{27}$ therefore $\mathrm{K}_{\mathrm{p}} \mathrm{c}_{\mathrm{p}} \ll<1$ and equation can be reduced to the pseudo-first order reaction,

$\mathrm{r}=\mathrm{k}_{\mathrm{app}} \mathrm{K}_{\mathrm{p}} \mathrm{c}_{\mathrm{p}}=\mathrm{k}_{\mathrm{obs}} \mathrm{c}_{\mathrm{P}}$

where $\mathrm{k}_{\mathrm{obs}}$ is the observed kinetic constant. The reaction rate constants were calculated by fitting the integrated rate equation of the first order kinetics $\left(\ln \mathrm{c} / \mathrm{c}_{0}=-\mathrm{k}_{\text {obs }} \mathrm{t}\right.$, where $\mathrm{c}$ and $c_{0}$ are the concentrations of phenol at time $t=t$ and $t=0$, respectively) and summarized in Table 1 . The observed kinetic constants of ZnS-CTA-MMT and ZnS-CTA were similar which agrees with the similar content of $\mathrm{ZnS}$. This fact is interesting and indicates that the $\mathrm{ZnS}$ nanoparticles enclosed in the MMT pores were in contact with the phenol molecules likely through the nanocomposite microspores.

The photodecompositon of phenol with MMT and with no photocatalysts proceeded according to the second order reaction kinetics. This situation occurs if $\Sigma \mathrm{K}_{\mathrm{i}} \mathrm{c}_{\mathrm{i}}$ can be neglected and it also holds that $\mathrm{K}_{\mathrm{p}} \mathrm{c}_{\mathrm{p}} \ll<1$ and $\mathrm{K}_{\mathrm{OH}} \mathrm{c}_{\mathrm{OH}} \ll 1$. Providing that $\mathrm{c}_{\mathrm{OH}} \approx \mathrm{c}_{\mathrm{p}}$ equation 9 comes to the pseudosecond order reaction:

$\mathrm{r}=\mathrm{k} \mathrm{c}_{\mathrm{OH}} \mathrm{c}_{\mathrm{p}} \approx \mathrm{k}_{\mathrm{obs}} \mathrm{c}_{\mathrm{p}}^{2}$

This presumption means that some phenol molecules released electrons forming the similar number of hydroxyl radicals. These kinetic data were fitted by the integrated rate equation for the second order reaction $\left(1 / \mathrm{c}=1 / \mathrm{c}_{0}+\mathrm{k}_{\mathrm{obs}} \mathrm{t}\right)$ (Table 1). The observed kinetic constants decreased with the increasing content of MMT and, thus, no catalytic activity of MMT was observed. Some reasons are scattering of UV radiation on the MMT particles and absorption of UV irradiation by the photodecomposition intermediates.

The possibility of the photo-Fenton reaction in the aqueous phase was verified. The concentration of $\mathrm{Fe}^{3+}$ could not be determined by spectrophotometric methods based on complex forming reactions because $\mathrm{Fe}^{3+}$ ions form complexes with phenol. Therefore, only the concentration of total iron was determined by AAS. As shown in Figure 3 it increased with the irradiation time up to $2.4 \mathrm{mg} \mathrm{L}^{-1}$ as a result of iron leaching from the $\mathrm{AlO}_{6}$ octahedra where they substitute $\mathrm{Al}^{3+}$. In spite of this, the photo-Fenton reaction producing hydroxyl radicals was not observed. It can be explained by the formation of complexes between $\mathrm{Fe}^{3+}$ ions and phenol and/or other photodecomposition intermediates. In addition, the amount of released $\mathrm{Fe}^{3+}$ was lower than its content in MMT.

\section{Intermediates of photodecomposition}

There are many various compounds that can be formed during the photodecomposition of phenol as mentioned above. In this work, they were analysed by the UV spectrometry (Figure 4), GC-MS and the TOC analysis (Figure 3 ) in the reaction dispersions/solutions after $1 \mathrm{~h}$ of the photodecomposition. The analyses were not performed in the ZnS-CTA dispersion due to the high content of CTAB complicating the analytical procedures.

As demonstrated in Figure 4 the phenol photodecomposition was characterized by the decrease of the absorbances at about $270 \mathrm{~nm}$ due to a ring-opening of phenol. The spectrum of phenol was used as a reference one. Using the absorbance at e.g. $238 \mathrm{~nm}$ (arrow in Figure 4) a degree of the decomposition of all organic compounds can be ordered in this manner: UV + ZnS-CTA-MMT $>$ UV > $\mathrm{UV}+$ MMT. The UV absorption spectra of various $\mathrm{Fe}^{3+}$ salts were also recorded. They exhibited strong absorption in the range of 200-400 nm, which is necessary for the

Table 1. Reaction rate constants of phenol photodecomposition

\begin{tabular}{lll}
\hline Decomposition & Observed kinetic constant & Regression coefficient \\
\hline UV+ZnS-CTA & $(0.537 \pm 0.072) \times 10^{-3}\left(\mathrm{~s}^{-1}\right)^{\mathrm{a}}$ & 0.9933 \\
$\mathrm{UV}+\mathrm{ZnS}-\mathrm{CTA}-\mathrm{MMT}$ & $(0.426 \pm 0.039) \times 10^{-3}\left(\mathrm{~s}^{-1}\right)^{\mathrm{a}}$ & 0.9947 \\
$\mathrm{UV}$ & $1.105 \pm 0.116\left(\mathrm{~L} \mathrm{~mol}^{-1} \mathrm{~s}^{-1}\right)^{\mathrm{b}}$ & 0.9945 \\
$\mathrm{UV}+\mathrm{MMT}\left(1.3 \mathrm{~g} \mathrm{~L}^{-1}\right)$ & $0.627 \pm 0.061\left(\mathrm{~L} \mathrm{~mol}^{-1} \mathrm{~s}^{-1}\right)^{\mathrm{b}}$ & 0.9954 \\
$\mathrm{UV}+\mathrm{MMT}\left(7.1 \mathrm{~g} \mathrm{~L}^{-1}\right)$ & $0.375 \pm 0.036\left(\mathrm{~L} \mathrm{~mol}^{-1} \mathrm{~s}^{-1}\right)^{\mathrm{b}}$ & 0.9956 \\
\hline
\end{tabular}

${ }^{\mathrm{a}}$ The first order reaction; ${ }^{\mathrm{b}}$ the second order reaction. 
photo-Fenton reaction and would be reduced by the presence of residual phenol and various organic intermediates.

Phenol and originating resorcinol were found by GC-MS as the majority organic compounds. The traces of acetophenone, dihydroxybenzenaldehydes, biphenyldiols, dioxydiphenyls were also identified with the fit of mass spectra $\geq 800$ (max. fit $=1000)$. Dichloromethane was used for a liquid-liquid extraction of reaction products and, therefore, some polar compounds could remain in the aqueous phase.

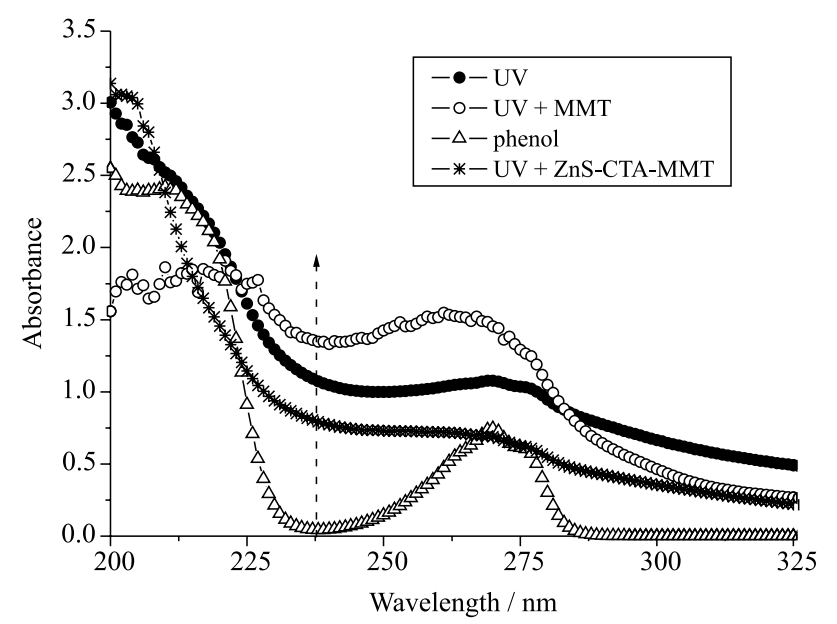

Figure 4. UV spectra of phenol after photodecomposition under various conditions.

The total concentration of organic compounds was characterized by determined TOC that was compared with TOC calculated from the phenol concentrations (TOC-phenol). TOC decreased at $60 \mathrm{wt} . \%$, which means that 40 wt. $\%$ of TOC was transferred to carbon dioxide. TOC-phenol decreased more rapidly because no other organic compound was taken into account in the calculation.

\section{X-ray diffraction of montmorillonite}

After the phenol photodecomposition in the presence of MMT, the MMT particles were separated, dried at $105{ }^{\circ} \mathrm{C}$ and examined by XRD. It was observed that the interlayer spacing $\mathrm{d}(001)$ changed from $1.13 \mathrm{~nm}$ of original MMT up to $1.27 \mathrm{~nm}$ of MMT after $2 \mathrm{~h}$. A linear dependence between $\mathrm{d}(001)$ and irradiation time $\mathrm{t}(\mathrm{h})$ up to $2 \mathrm{~h}$ was obtained:

$\mathrm{d}(001)=0.068 \mathrm{t}+1.13(\mathrm{n}=6, \mathrm{r}=0.9926)$

We found in our earlier work ${ }^{27}$ that $\mathrm{d}(001)$ of MMT intercalated by phenol increased of about $0.17 \mathrm{~nm}$. Therefore, the intercalation of phenol and some intermediates can be assumed. The intercalated compounds could likely limit the leaching of $\mathrm{Fe}^{3+}$ ions to the aqueous phase that was demonstrated by the low concentrations of total iron in Figure 3.

\section{Conclusions}

The ZnS nanoparticles stabilized by CTA ions were deposited on montmorillonite forming the stable ZnS-CTA-MMT nanocomposite. This nanocomposite was tested as the catalyst for the photodecomposition of phenol by UV irradiation. For comparison, the experiments with ZnS-CTA, montmorillonite and with no catalyst (only UV) were also tested and the photodecomposition efficiency can be ordered as $\mathrm{UV}+\mathrm{ZnS}-\mathrm{CTA}-\mathrm{MMT} \approx \mathrm{UV}+\mathrm{ZnS}-\mathrm{CTA}>$ $\mathrm{UV}>\mathrm{UV}+\mathrm{MMT}$.

The reaction kinetics of the photodecomposition with the $\mathrm{ZnS}$ nanoparticles both fixed in the nanocomposite and as the free $\mathrm{ZnS}-\mathrm{CTA}$ micelles corresponded to the pseudo-first order reaction model. It indicates that the $\mathrm{ZnS}$ nanoparticles produced the high concentrations of hydroxyl radicals $\left(\mathrm{c}_{\mathrm{OH}}>>\mathrm{c}_{\mathrm{p}}\right)$. Taking into account the low content of $\mathrm{ZnS}(7 \mathrm{wt} . \%)$ the nanoparticles exhibited the very high photodecomposition efficiency. In other cases, the photodecomposition followed the pseudo-second order reaction model. The hydroxyl radicals were produced in lower concentrations by the reactions of electrons released from excited phenol and oxygen dissolved in water.

The MMT catalytic activity based on the photo-Fenton reaction referred in the literature was not observed. MMT decreased the decomposition reaction rates likely due to the UV irradiation scattering. It implies that a question of the clays photocatalytic activity is a complex and still open problem for further investigations and discussions. In next research the photocatalytic activity of the $\mathrm{ZnS}$ nanoparticles will be tested for the decomposition of other environmental pollutants.

\section{Acknowledgments}

The financial supports of the Grant Agency of the Czech Republic (P107/11/1918), Regional Material Technology Research Centre (CZ.1.05/2.1.00/01.0040) and VŠB-Technical University of Ostrava (student's grants SP2012/29 and SP2012/196) are gratefully acknowledged. The authors thank Dr. Mamulová-Kutláková for measurement of the XRD patterns.

\section{References}

1. Mills, A.; Le Hunte, S.; J. Photochem. Photobiol., A 1997, $108,1$. 
2. Hoffmann, M. R.; Martin, S.T.; Choi, W.; Bahnemann, D.W.; Chem. Rev. 1995, 95, 69.

3. Buxton, G. V.; Greenstock, C. L.; Helman, W. P.; Ross, A. B.; J. Phys. Chem. Ref. Data 1988, 17, 513

4. Wu, F.; Li, J.; Peng, Z.; Deng, N.; Chemosphere 2008, 72, 407.

5. Kibanova, D.; Trejo, M.; Destaillats, H.; Cervini-Silva, J.; Catal. Commun. 2011, 12, 698.

6. Gournis, D.; Karakassides, M. A.; Petridis, D.; Phys. Chem. Miner. 2002, 29, 155.

7. León, M. A.; Castiglioni, J.; Bussi, J.; Sergio, M.; Catal. Today 2008, 133-135, 600 .

8. Zhang, X.; Wu, F.; Deng, N.; Pozdnyakov, I. P.; Glebov, E. M.; Grivin, V. P.; Plyusnin, V. F.; Bazhin, N. N.; React. Kinet. Catal. Lett. 2008, 94, 207.

9. Wang, Z.; Huang, L.; Du, L.; Sheng, L.; Lv, B.; J. Environ. Eng. 2010, Jan, 152.

10. Liu,Y.; Zhang, X.; Wu, F.; Appl. Clay Sci. 2010, 49, 182.

11. Navalon, S.; Alvaro, M.; Garcia, H.; Appl. Catal., B 2010 , $99,1$.

12. Herney-Ramirez, J.; Vicente, M. A.; Madeira, L. M.; Appl. Catal., B 2010, 98, 10.

13. Prousek, J.; Chem. Listy 1996, 90, 307.

14. Schech, C. K.; Frimmel, F. H.; Water Res. 1995, 29, 2346.

15. Dušek, L.; Chem. Listy 2010, 104, 846.

16. Wood, P. M.; Biochem. J. 1988, 253, 287.
17. Kozák, O.; Praus, P.; Kočí, K.; Klementová, M.; J. Colloid Interface Sci.2010, 352, 244.

18. Praus, P.; Dvorský, R.; Horínková, P.; Pospíšil, M.; Kováŕ, P.; J. Colloid Interface Sci. 2012, 377, 58.

19. Alapi, T.; Dombi, A.; J. Photochem. Photobiol., A 2007, 188, 409.

20. Svetlichnyi, V. A.; Chaikovskaya, O. N.; Bazyl, O. K.; Kuznetsova, R. T.; Sokolova, I. V.; Kopylova, T. N.; Meshalkin, Yu. P.; High Energy Chem. 2001, 35, 288.

21. Vogel, F.; Harf, J.; Hug, A.; von Rohr, P. R.; Environ. Prog. 1999, $18,7$.

22. Abbas, O.; Rebufa, C.; Depuy, N.; Kister, J.; Talanta 2008, 77, 2000.

23. Ahmed, S.; Rasul, M. G.; Martens, W. N.; Brown, R.; Hashib, M. A.; Desalination 2010, 261, 3.

24. Praus, P.; Dvorský, R.; Pustková, P.; Kozák, O.; Adv. Sci. Eng. Med. 2011, 3, 113.

25. Brosillon, S.; Lhomme, L.; Vallet, C.; Bouzaza, A.; Wolbert, D.; Appl. Catal., B 2008, 78, 232.

26. Kumar, K. V.; Porkodi, K.; Rocha, F.; Catal. Commun. 2008, 9,82 .

27. Kostelníková, H.; Praus, P.; Turicová, M.; Acta Geodyn. Geomater. 2008, 5, 83.

Submitted: April 10, 2012 Published online: October 23, 2012 